\title{
Evaluating Volunteer Motivation for Sea Turtle Conservation in Florida ${ }^{1}$
}

\section{Bianca M. Bradford and Glenn D. |srael ${ }^{2}$}

Sea turtles are one of the most endangered groups of animals in the world, and Florida's many beaches are important to their survival. Five of the seven species of sea turtle listed as threatened or endangered under the United States Endangered Species Act use Florida beaches to lay their eggs and reproduce. Since 1979, the Florida Fish and Wildlife Conservation Commission (FWC) has conducted the annual Survey of Nesting Beaches in order to understand trends in sea turtle nesting. The survey would not be possible without the time and energy contributed by hundreds of volunteers around the state.

Understanding volunteer motivation has been widely recognized by both researchers and managers as a valuable component of volunteer management (Cnaan \& Goldberg-Glen, 1991; Harrison, 1995). Some studies have shown that highly motivated volunteers serve longer than volunteers who do not have their needs met through service (Omoto \& Snyder, 1995). No study, however, has fully explored the roles that volunteers play in sea turtle conservation.
To fill this gap, we conducted a study to reveal the motivations and experiences of people who volunteer for sea turtle conservation in Florida. We focused on three questions: What kind of people are sea turtle volunteers? Why do they volunteer? And, what do volunteers do? We collected data from volunteers and their supervisors to answer these questions.

\section{WHAT KIND OF PEOPLE ARE SEA TURTLE VOLUNTEERS?}

Approximately two-thirds of the 382 volunteers who responded to the survey identified themselves as female. The volunteers who responded to our survey worked for one of the 26 permit holders who provided names of their volunteers. ${ }^{3}$ Four permit holders accounted for almost half (47.8\%) of all volunteers.

Though most volunteers were mature adults (the average age was 53), the youngest was 14 years old and the oldest was 82. Middle-aged and older volunteers may be more numerous because Florida has a higher percentage of older adults than the rest of the country. Results from the 2000 Census show that

1. This document is AEC 372, a publication of the Agricultural Education and Communication Department, Florida Cooperative Extension Service, Institute of Agricultural and Food Sciences, University of Florida. Publication date May, 2004. Visit the EDIS website at http://edis.ifas.ufl.edu.

2. Bianca M. Bradford, former graduate student, and Glenn D. Israel, Professor, Department of Agricultural Education and Communication, Institute of Food and Agricultural Sciences, University of Florida, Gainesville, 32611. This survey was supported by the National Science Foundation through a Graduate Research Fellowship to Bianca Bradford. Additional support was provided by supplemental funding from the Graduate School at the University of Florida. The authors wish to thank Tracy Irani and Rick Rudd for comments on an earlier draft of this fact sheet.

The Institute of Food and Agricultural Sciences (IFAS) is an Equal Employment Opportunity - Affirmative Action Employer authorized to provide research, educational information and other services only to individuals and institutions that function without regard to race, creed, color, religion, age, disability, sex, sexual orientation, marital status, national origin, political opinions or affiliations. For information on obtaining other extension publications, contact your county Cooperative Extension Service office. Florida Cooperative Extension Service / Institute of Food and Agricultural Sciences / University of Florida / Larry R. Arrington, Interim Dean 
people aged 65 and older comprised only $12.4 \%$ of the nation's population but made up $17.6 \%$ of Florida's population (US Census Bureau, 2000). As the national population ages, the average age of sea turtle volunteers will likely increase.

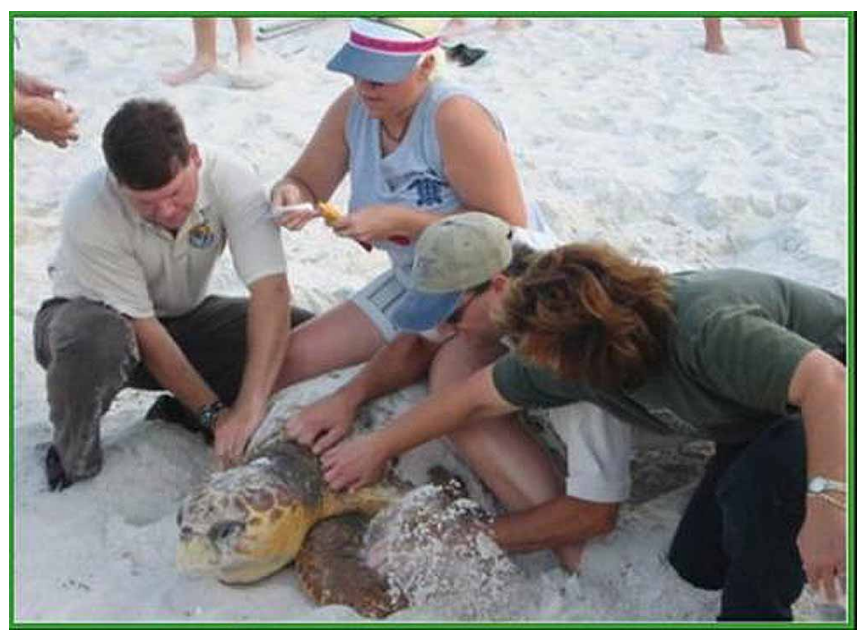

Figure 1. Volunteers assist biologists in tagging a nesting loggerhead turtle. Credits: Photo courtesy of the St. Andrew Bay Resource Management Association, Panama City, Florida

Sea turtle volunteers were well-educated. Approximately $31 \%$ of volunteers had attended at least some college, and 22\% had earned a bachelors degree. Graduate education was not uncommon for this group, as $10 \%$ of volunteers had completed some graduate courses and $28 \%$ reported earning a graduate or professional degree. Turtle volunteers had more years of formal education than most Floridians. According to the 2000 Census, only $8 \%$ of Florida residents aged 25 and older had completed a graduate or professional degree (US Census Bureau, 2000).

Approximately $45 \%$ of respondents reported that they did not work for pay. Full-time employees, those working 35 or more hours per week, made up $31 \%$ of the respondents. Of the 102 volunteers who worked full time, approximately half of the same group reported an annual income of more than $\$ 50,000$.

About $11 \%$ of volunteers did not answer the ethnicity question, but of those who did, nearly all (99\%) identified themselves as "not

Spanish/Hispanic/Latino." When asked to choose one or more racial categories, $98 \%$ identified themselves as White.
Respondents had volunteered for sea turtle conservation for an average of 4.3 years. When asked if they belonged to a group that worked for sea turtle conservation, $69 \%$ of the respondents said yes. When asked if they had invited someone to join their turtle group, an equal percentage $(69 \%)$ of members indicated they had. The average tenure of group membership was just over 4 years.

In summary, the profile of sea turtle volunteers is different from Florida's residents as a whole.

Educational achievement and ethnicity provide two striking examples of contrasts between survey respondents and the general population of the state. As mentioned in the results, more than $98 \%$ of turtle volunteers identified as White. While the racial data varies widely across Florida counties, the 2000 Census found that White people made up only $78 \%$ of the states population.

\section{WHY DO PEOPLE BECOME SEA TURTLE VOLUNTEERS?}

In order to measure volunteer's motivations, we asked each person 30 questions (adapted from Clary, Snyder, Ridge, et al. (1998) Volunteer Functions Inventory) and then combined their answers into six dimensions. Each of the six dimension scores could range between 1 and 7, with a score of 1 meaning "Not at all important" and a score of 7 denoting "Extremely important." We then computed the mean value of each motive for all 382 responses.

Overall, our data show that people volunteer for different reasons and most do so for more than one reason. Helping and protecting sea turtles is the most important factor that motivates sea turtle volunteers. Respondents gave this category an average score of 6.45 on a Likert-type scale of 1 to 7 , indicating this is an extremely important reason for becoming a volunteer (Table 1). Showing compassion and concern for other people is the second-most important reason for volunteering. Career development was the least salient motive for sea turtle volunteers, which is not surprising given the demographic profile of volunteers (see Figure 2).

People who volunteered for the 2002 Survey of Nesting Beaches were highly motivated. A desire to do something to help sea turtles was the most highly 


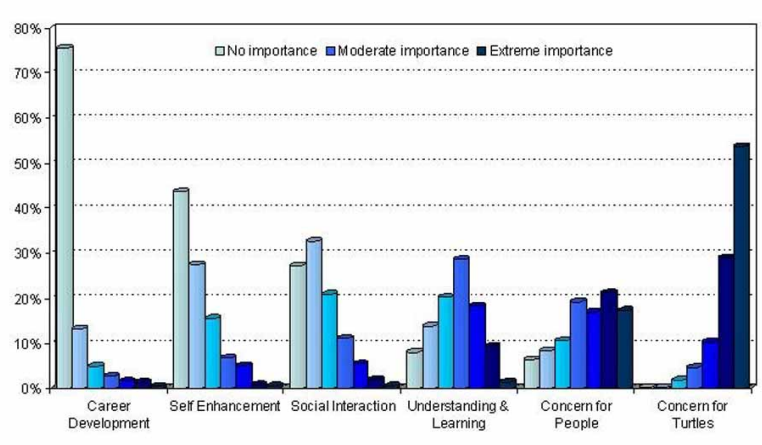

Figure 2. Distribution of scores on 6 categories of volunteer motivation. Credits:

rated motive, but subsets of volunteers were driven by the desire to help their careers or by a belief in helping other people. Younger people were more likely to volunteer for career-related benefits. Gender affected motivation through an interaction with education. Highly educated women were more likely than similarly educated men to volunteer because of their concern for turtles. Men were also less motivated by a desire to help fellow human beings than their female peers. Few respondents admitted volunteering because it helps them make new friends, but they generally agreed that making friends was an experience they had as a result of volunteering for turtle conservation.

Like people in other voluntary organizations, participants in the nest-monitoring survey reported multiple reasons for volunteering. However, the Volunteer Functions Inventory (VFI) was not a perfect fit in providing a structure for motivation. In many ways, Floridians who monitor sea turtle nests are similar to other kinds of volunteers. Like volunteers for AIDS organizations, turtle volunteers appear to be driven by a need to live out deeply held values (Omoto \& Snyder, 1995). Recent studies of volunteerism have found that volunteers receive a variety of benefits from their service (Braker et al., 2000; Schrock et al., 2000). Our questionnaire included several indirect measures of satisfaction, all of which infer that sea turtle volunteers are content with their experiences. Survey respondents strongly agreed that they were helping sea turtles, which satisfies their primary motivation for volunteering.
The majority of volunteers are so enthusiastic about their work that they invited others to help them and to become members of turtle groups. On average, volunteers in this study had participated for more than four years, which implies that the associated costs of volunteerings are outweighed by the rewards of service.

\section{WHAT DO SEA TURTLE VOLUNTEERS DO?}

Volunteers participated in a number of different activities during the 2002 nesting season, ranging from patrolling the beach to giving educational presentations about turtles (Table 2, Figure 3, Figure 4, Figure 5).

Permit holders were asked to indicate whether their volunteers had engaged in any of six different activities. Respondents indicated that they used volunteers in various ways, but finding and marking turtle nests was the most common activity (Table 3).

\section{Permit Holders' Opinions}

Of the 65 permit holders who responded to our survey, roughly three-quarters reported working with volunteers in 2002. A similar portion, $71 \%$, said that they worked with volunteers in 2001. Respondents reported working with a total of 1550 additional personnel, of whom 1056 (68\%) were considered volunteers. Survey respondents reported using an average of 23 volunteers during the 2002 nesting season. On average, $84 \%$ of the 2002 cohort participated in 2001. Permit holders were also asked to predict how many of the 2002 volunteers would return for the 2003 nesting season. Among the permit holders who expected to work with volunteers in 2003 , the average predicted return rate was $84.6 \%$.

All permit holders, regardless of whether they supervised volunteers in 2002, were asked to respond to 12 statements about working with volunteers. Most permit holders held a positive attitude toward volunteers. Respondents generally agreed that using volunteers helps them to accomplish more and improved their relationships with the public. They also agreed that volunteers are eager to learn and willing to work hard. Permit holders generally disagreed with the assertions that volunteers are 


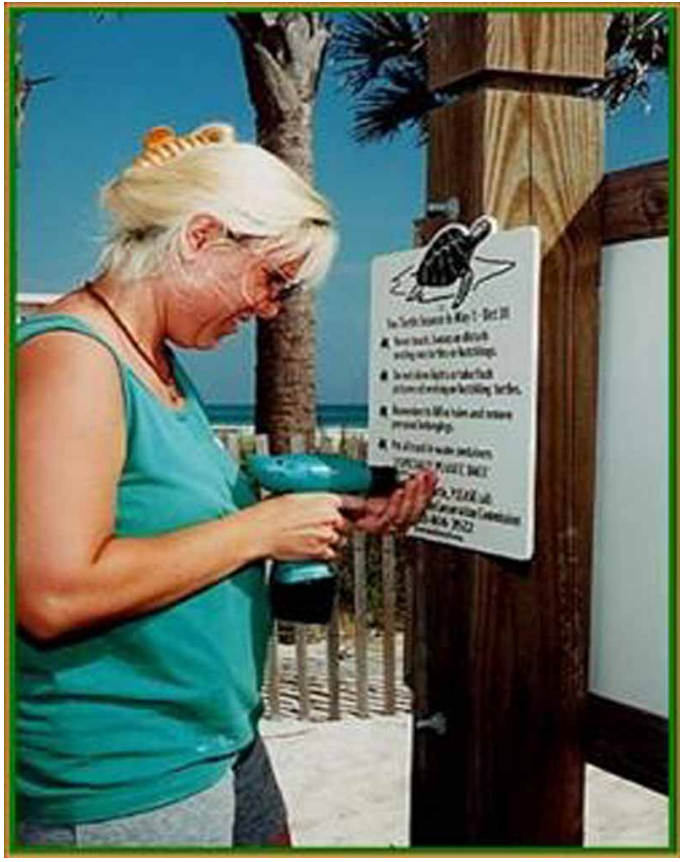

Figure 3. A volunteer posts a sign informing beachgoers about turtle nesting season. Credits: Photo courtesy of the St. Andrew Bay Resource Management Association, Panama City, Florida

unreliable and lack the scientific training to help carry out nesting surveys. Respondents strongly disputed the idea that volunteering for sea turtle conservation is dangerous. On average, permit holders slightly agreed that paid workers are more committed than volunteers, but they responded neutrally to the statement "Paid employees perform better than volunteers."



Figure 4. Volunteers relocate eggs from a loggerhead nest to prevent them from being flooded. Credits: Photo courtesy of the St. Andrew Bay Resource Management Association, Panama City, Florida
We asked permit holders to name their biggest concern about working with volunteers. The most frequently mentioned problem, cited by $20 \%$ of respondents, was inaccurate or incomplete data collection, which could result in missed and unmarked nests. Permit holders mostly attributed this problem to a lack of experience in identifying false crawls and nests; only one respondent blamed it on the lack of biology knowledge among volunteers. Finding reliable volunteers was an important issue for approximately $11 \%$ of respondents, who were specifically concerned about finding enough committed volunteers to sustain the monitoring program for the long duration of the nesting season.



Figure 5. Elementary students watch as volunteers excavate a green turtle nest. Credits: Photo courtesy of the St. Andrew Bay Resource Management Association, Panama City, Florida

\section{DISCUSSION}

Our study found that most individuals volunteered in sea turtle conservation for more than one reason. Concern for sea turtles was the dominant motive for nearly everyone and this was commonly complemented by either a concern for other people or a desire to learn and understand sea turtles and turtle ecology. This pattern of motivation suggests that permit holders must tailor volunteer activities that address these different motivations in order to maximize the latter's time and talent.

Permit holders who responded to the survey were generally positive about working with volunteers to collect data. Respondents believed that volunteers help them to accomplish more and improve public 
relations. While some permit holders are concerned about inaccurate data collection and turnover among trained volunteers, most permit holders were pleased with their performance and appreciated their dedication. As one permit holder wrote, "We can't thank them enough."

\section{RECOMMENDATIONS}

\section{- Invite volunteers to training workshops for} permit holders. Currently, FWC turtle program staff work closely just with permit holders (Conti, personal communication, 2002). Permit holders are encouraged to bring their volunteers to the annual training workshops but a substantial portion of the volunteers in the study reported never having attended such a workshop. The FWC Turtle Program staff may want to issue individual e-mail or mailed invitations to volunteers. In-depth training might be a powerful incentive for individuals who want to learn more about sea turtle conservation.

\section{- Use current volunteers to recruit new ones.}

Most volunteers can be expected to recruit someone else to join, thus permit holders should use current volunteers as their primary method of recruitment. In most voluntary associations, new members tend to mirror the socio-demographic traits of current members (Popielarz and McPherson, 1995). If volunteer program managers desire a more ethnically or economically diverse group, they will have to employ supplemental methods.

\section{- Target retirees as potential volunteers.}

Permit holders need helpers who are available and willing to commit to the long nesting season. Unlike other studies of volunteers for environmental organizations (King and Lynch, 1998), retirees and others who did not work at all far outnumbered full-time employees.

- Evaluate volunteers regularly. Periodic meetings between volunteers and their supervisors offer opportunities to resolve problems for the mutual benefit of both parties. Few permit holders take the opportunity to offer a formal review at the end of the season but such evaluations, whether written or verbal, can also help to increase an individual's sense of loyalty and strengthen ties with the organization (Medaugh, 1999).

- Retain experienced volunteers. Experienced volunteers are a valuable resource for training novices. Permit holders also cited lack of experience as a factor in incomplete or wrong nesting information. The exact amount of time needed to increase accuracy is unknown, but supervisors consistently linked better performance with more experience. One way to increase retention is through volunteer recognition activities. FWC can support permit holders by recognizing the contributions they and their volunteers make. Public recognition of volunteers is one option; personal communication with turtle patrol members may also be sufficient at improving volunteers' feelings of appreciation.

The continued existence of Florida's sea turtle volunteer programs will require sustained support from volunteers, permit holders, and the FWC. Volunteers indicated that the program has usually succeeded in meeting their needs for useful training, and has satisfied their desire to do something to help sea turtles. High retention rates of volunteers are a strong indicator that the program is sustainable in its current form.

\section{REFERENCES}

Braker, M.J., Leno, J.R., Pratt, C.C., \& Grobe, D. (2000). Oregon Extension volunteers: Partners in action. Journal of Extension, 38.

Clary, E.G., Snyder, M., Ridge, R.D., Copeland, J., Stukas, A.A., Haugen, J., Miene, J. (1998). Understanding and assessing the motivations of volunteers: A functional approach. Journal of Personality and Social Psychology, 74, 1516-1530.

Cnaan, R.A., \& Goldberg-Glen, R.S. (1991). Measuring motivation to volunteer in human services. Journal of Applied Behavioral Science, 27, 269-284.

Dillman, D.A. (2000). Mail and internet surveys: The tailored design method. New York: John Wiley \& Sons. 
Harrison, D.A. (1995). Volunteer motivation and attendance decisions: Competitive theory testing in multiple samples from a homeless shelter. Journal of Applied Psychology, 80, 371-385.

King, K.N., \& Lynch, C.V. (1998). The motivation of volunteers in The Nature Conservancy -Ohio Chapter, a non-profit environmental organization. The Journal of Volunteer Administration, (XVI), 5-11.

Medaugh, B. (1999). Volunteer evaluations-from a volunteers perspective. Journal of Volunteer Administration, Winter 1999, 6-10.

Omoto, A.M., \& Snyder, M. (1995). Sustained helping without obligation: Motivation, longevity of service, and perceived attitude change among AIDS volunteers. Journal of Personality and Social Psychology, 68, 671-686.

Popielarz, P.A., \& McPherson, J.M. (1995). On the edge or in between: Niche position, niche overlap, and the duration of voluntary association memberships. American Journal of Sociology 101, 698-720.

Schrock, D.S., Meyer, M., Ascher, P., \& Snyder, M. (2000). Benefits and values of the master gardener program. Journal of Extension, 38. Retrieved April 22, 2003 from

http://www.joe.org/joe/2000february/rb2.html

United States Census Bureau. (2000). Florida QuickFacts. Retrieved 23 April 2003 from http://quickfacts.census.gov/qfd/states/12000lk.html

\section{APPENDIX: SURVEY PROCEDURES}

\section{Marine Turtle Permit Holder Survey}

We conducted mail surveys of two groups of Floridians who are active in sea turtle conservation. The first survey targeted permit holders, a specially-trained group of volunteers who work with marine turtles. We developed a four-page questionnaire to measure permit holders' use of volunteers and their attitudes about working with volunteers.
Meghan Conti of the Florida Fish and Wildlife Conservation Commission supplied us with a list of the permit holders for the Survey of Nesting Beaches. All 74 permit holders were invited to participate in the survey, which was conducted in August 2002. We used a system of four contacts to increase the response rate. Sixty-five of the 74 permit holders returned a completed or partially complete questionnaire, resulting in a response rate of $85.1 \%$.

\section{Sea Turtle Volunteer Survey}

The final question on the permit holder's survey asked the respondent to send us the names and addresses of any volunteers. We used these names to build a mailing list for our second survey of sea turtle volunteers. Only 35 of the 46 permit holders who used volunteers in 2002 agreed to provide names and addresses of volunteers. Ultimately, only 26 permit holders were represented in the volunteers study because some permit holders who agreed to provide names did not provide a list.

We constructed an 8-page questionnaire to measure the behavior, attitudes, motivations, outcomes, and demographic characteristics of sea turtle volunteers. The Tailored Design Method guided the processes of questionnaire design and survey implementation (Dillman, 2000). Our mailing strategy used three contacts to reduce non-response error. The overall response rate was 382 out of 443 , approximately $86 \%$.

Volunteer motivation was measured using the 30-item Volunteer Functions Inventory (Clary, Snyder, Ridge, Copeland, Stukas, Haugen, and Miene, 1998). Inventory items represent 6 different categories of motivation labeled Career, Social, Values, Enhancement, Protective, and Understanding. The Volunteer Functions Inventory has been widely used to measure motivation among adult volunteers in various settings.

A principal-components factor analysis of 30 items about reasons for volunteering showed the existence of six underlying factors, as predicted by the VFI. A principal-axis factor analysis with oblique rotation confirmed six underlying factors, although these differed somewhat from the factors identified by Clary et al. (1998). The pattern of factor loadings 
suggests the presence of three distinct factors that correspond to the Career, Social, and Understanding factors. We created a composite score for each dimension by summing the answers to the items, then dividing by the number of items in the subscale.

\section{Additional Notes:}

3. Sea turtle permit holders are specially trained volunteers who have been authorized by the Florida Fish and Wildlife Conservation Commission to monitor turtle nests. While the permit holders are themselves volunteers because they do not receive financial compensation for their assistance with the Survey of Nesting Beaches, they were considered supervisors for the purposes of this study. 
Table 1. Mean scores on 6 volunteer motivation factors.

\begin{tabular}{||l|c||}
\hline \hline Motivation category & Average Score \\
\hline Concern for Turtles & 6.45 \\
\hline Concern for People & 4.84 \\
\hline Understanding \& Learning & 4.35 \\
\hline Social Interaction & 2.83 \\
\hline Self-Enhancement & 2.42 \\
\hline Career Development & 1.63 \\
\hline \hline
\end{tabular}

Table 2. Volunteer duties.

\begin{tabular}{||l|c||}
\hline \hline Duties & $\%$ \\
\hline Patrolled the beach for nesting activity & 93.4 \\
\hline Marked turtle nests & 77.0 \\
\hline Relocated turtle nests & 34.0 \\
\hline $\begin{array}{l}\text { Expressed concern about lighting ordinances } \\
\text { to local government }\end{array}$ & 30.6 \\
\hline Reported a turtle stranding & 20.0 \\
\hline \begin{tabular}{l} 
Led a group on a turtle watch \\
\hline $\begin{array}{l}\text { Given a presentation or talk about sea } \\
\text { turtles }\end{array}$
\end{tabular} & 19.4 \\
\hline $\begin{array}{l}\text { Talked to the media about turtle nesting } \\
\text { season }\end{array}$ & 13.6 \\
\hline $\begin{array}{l}\text { Written a letter to the editor about sea } \\
\text { turtles }\end{array}$ & 4.5 \\
\hline \hline
\end{tabular}

Table 3. Duties signed by permit holders and volunteers.

\begin{tabular}{||l|c||}
\hline \hline Duty & $\%$ \\
\hline Patrolled beaches to look for nesting activity & 93.5 \\
\hline Excavated nests after eggs have hatched & 73.9 \\
\hline \hline
\end{tabular}


Table 3. Duties signed by permit holders and volunteers.

\begin{tabular}{||l|c||}
\hline \hline Gave slide shows or presentations to groups & 53.0 \\
\hline Assisted with turtle walks & 34.8 \\
\hline Led turtle walks & 21.4 \\
\hline Tagged adult sea turtles & 9.5 \\
\hline
\end{tabular}

